\title{
Automation of Solar Solution Toolkit License
}

\author{
Akash A.Muttoor \\ Dept of Master of Computer Applications \\ Gogte Institute of Technology, \\ Belagavi, Karnataka, India
}

\author{
Mrutyunjaya.S.Emmi \\ Faculty, Department of MCA \\ Gogte Institute of Technology, \\ Belagavi, Karnataka, India
}

\begin{abstract}
"Solar Solution Toolkit License" is a web application which is mainly for a solar company. As installing solar takes lot of paper \& manual work, to avoid this heavy work this application will be used. Once the customer comes in contact with the user, leads and installation Quotation would be generated. The details of the customer would be stored in lead module for further reference. Upon the interest of the customer, user sends him quotes depending on his power bills.
\end{abstract}

The aim of this paper is to improvise the existing manual working process of Solar Installation to digital productivity manner with the help of some new technologies. My experimental analysis shows that the existing working process can be overcome with digital process in terms of time saving, data or information storage, etc. This section will include discussion and interactive examples of lead screening, site visits, proposal preparation and presentation, closing, documentation and writing up the sale.

Keywords : Home Location, Solar Panel, Solar Report, Google Maps API, Lead Generation

\section{INTRODUCTION}

"Solar Solution Toolkit" is a tool to generate leads and provides solar panel installation rough diagram for its end users. The Solar Solution Toolkit provides financial analysis and software to solar installers to help them make a strong sales case for solar electricity to their customers. Solar Solution Toolkit License is fully responsive web-application, can be used mobile as well as tablets. There are totally 3 users of this "Solar Solution Toolkit".

1. Users

2. Sub Company Admin/Website

3. Super Admin

Users are the ends users, who can enter his roof address and electricity bill. And start designing Solar system on his roof with following simple steps:

1.1 Solar System Design: Here user can see how his roof looks with these solar panels and how to maximize returns on investment. User can find his roof and place panels by himself own and finalize the solar panels.

1.2 System Requirements: User will get all he wants to know about his Solar System, how much KW system, required roof area to install system, average solar hours, system energy production, solar installation savings and lot more.

1.3 Savings Report: User can get his solar savings report generated in PDF format. A tailor made financial and solar savings model that is specific to user's roof characteristics and reflects your model assumptions and property features.

Companies are the users, who want to use the SST License Web Application. And they can get their license by signing up on SST website with following simple steps:

2.1 Get License: Companies can buy our SST License application by signing up on our website. Once they sign up for the license, a company will be activated by our Super Admin and provided the necessary login credentials to them to our web application.

2.2 Lead Generation and Site Customization: Once the Solar company user gets license, he can generate his own leads from his clients/customers. A company can customize his own site with our Site Customization feature.

Super Admin are the main SST application holder, who manages the SST License Web Application. And they activate companies who sign up for SST License: 
3.1 New Request: New requests are the companies who wants use SST license are managed in this module. Here Super Admin can activate or deactivate the SST License requests.

3.2 Company Details: A Company detail holds all the company details who sign up for SST License. Super admin can make changes to his clients according to their wish.

\section{PROPOSED SYSTEM}

Customer who draws Solar Panels Virtually on their roofs can be tracked easily and follow up will be provided to those customers by calling or by emailing to them. Companies who purchases SST License they can customize their SST Licensed website pages according to their needs. Company who purchases SST License can add their own offers and can generate their customized reports.

In proposed system, statistically graph can be produced and log (timelines) will be managed for each and every tasks of web-application. Through our proposed system one can save his most valuable time period and required cost of installation testing.

Super admin have authority to activate or deactivate the company which is requested for Solar Solution Toolkit License. Super Admin can activate and deactivate company and also fetch all company details and can deliver notifications to the companies. Super Admin has all the rights to change the defaultassumptions, site-label and report-values. End users can use this website application by visiting to our website URL and can test their own Solar panel installation on their house roofs. End-User can create a PDF report of the solar and his savings report through this website application.

\section{TOOLS AND TECHNOLOGIES}

\section{Tools}

PHP strome: PHP Strome IDE is excellent tool for PHP-development. It has built in PHP keys libraries which will help in developing the web-applications very fast. PHP-Strome highlights the occurred issues and helps to debug the errors.

AngularJS: AngularJS (commonly referred to as "Angular" or "Angular.js") is a complete JavaScriptbased open-source front-end web application framework mainly maintained by Google and by a community of individuals and corporations to address many of the challenges encountered in developing single-page applications.

\section{Technologies}

Front-end: HTML5, CSS, JQuery, AJAX and Angular.

Back-end: PHP and MySQL

PHP: PHP Pre-processor Hypertext is open source programming language which is mainly used in web development. This is one of the secured language it have several versions and latest version is 5.5.35.

MySQL: SQL-Structured query language used to store and rearview the data from database.

\section{DETAILED DESIGN}

There are totally two use case outlines of the system, those are:

- Company Use Case and

- Super Admin use Case.

\section{Company Use Case Design:}

Company use case diagrams shows the admin side working environment. This will holds all the working components of the company admin. Admin can make changes to the web application and new categories according to his needs. All the sub companies will be having below working modules as shown in use case diagram: 


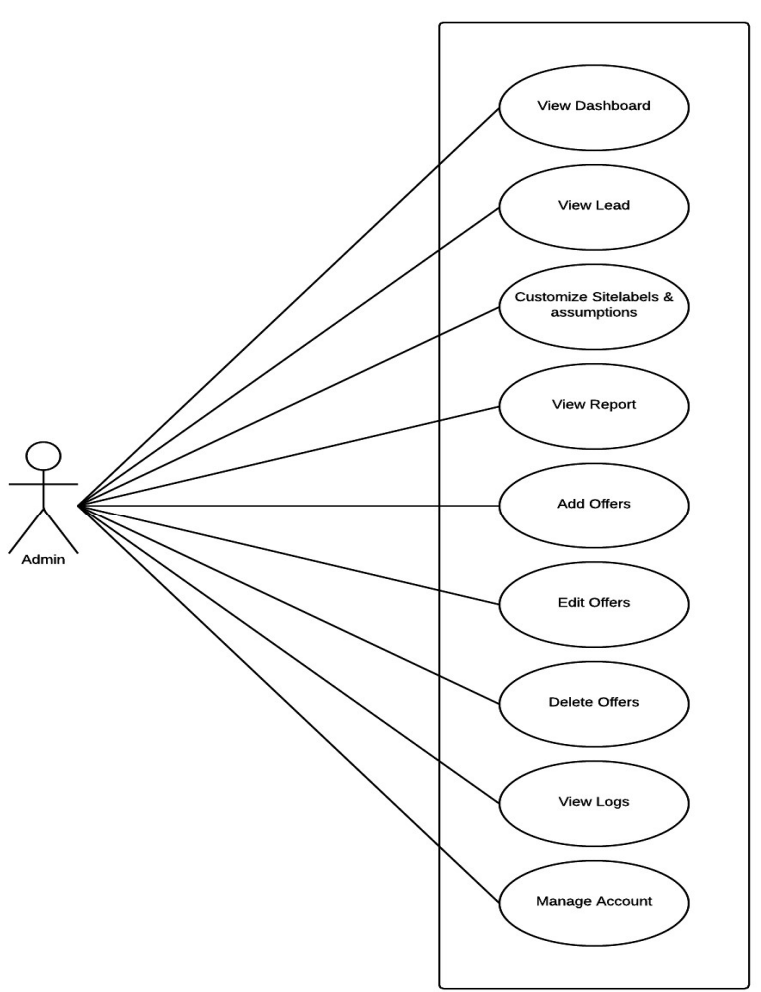

Fig 4.1 Company use case

\section{Super Admin Use Case Design:}

Super Admin will be main authority holder who has all the access to the application. He will be working with all the companies and new SST License work.

Super admin can activate and deactivate the companies who sign up for the SST License application.

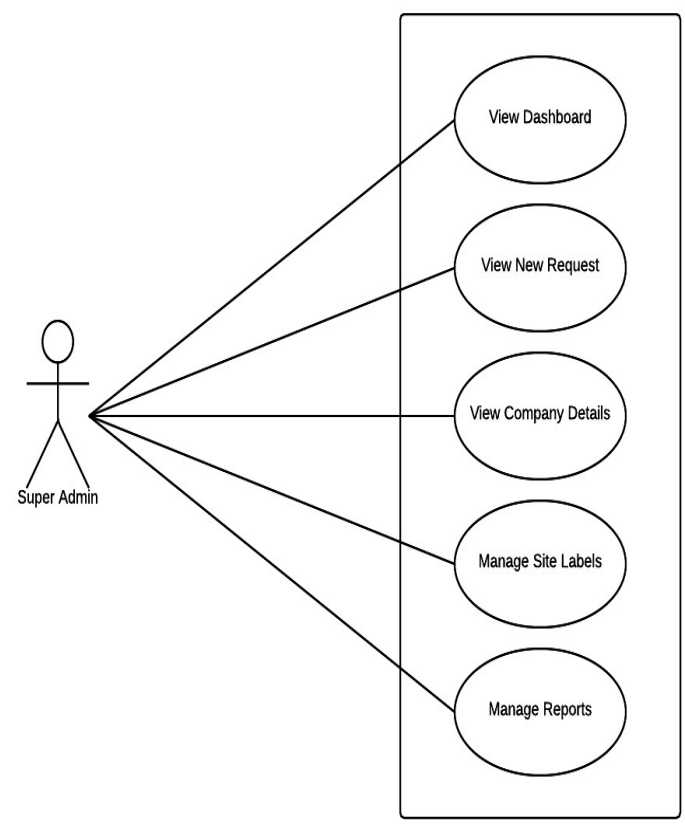

Fig 4.2 Super-admin use case
Units

Step 1: Get License

Clients can visit our website and find Get License button and provide some necessary information then he can get license to use our application.

Step 2: Processing

The request from clients will be processed by the our SST team members and will generate a new login credentials for the client.

Step 3: Configuration

Clients can immediately configure his own account by filling basic facts about the client.

Step 4: SST Link

As soon as you finish up with the Step 3 configuration, the system will make quick SST URL's for you.

Step 5: Customize Assumptions

Clients can customize their web site which is generated in step 4 SST URL's according to their necessary information.

Step 6: Select Template report

Clients can generate his own report by selecting some of our existing templates and send it to his own customers.

Step 7: Customize Report Template

He can customize selected report template according to their customer requirements. Client can add Company Logo, Set Colors, Impressive labels and many more.

Step 8: Customization of SST website

Client can even customize SST website according to their requirements. Client can add his own company logo, his own Primary colors, expressive labels and many more.

Step 9: Promotion of SST web URL

Now client can Promote his own SST web URL and video clips on website, emailing, and marketing materials as a free tool for prospects, agents \& sales reps to view/download report. This acts as the readymade quote for clients end users. 
Step 10: Leads to your inbox

Seat back and relax all customers prospects will then click on your SST URL link \& this directs end users to the site where they will key in their home address and contacts details and view/download customized report, with details like suggested system size, their savings over 25 years, bills with \& without solar.

Step 11: Solar panel design

End user can design installation of the solar panels on their building roof area.

Step 12: Solar panel report generation

End users can download the generated solar panel report rough copy from the website.

\section{Functions}

Login: This web application has two types of logins one is for company login and the other one is for Super-Admin login. The login will be based on necessary credentials. The validation for both the user is effective to each other.

Dashboard: Dashboard has overall overview of the modules of web application. Dashboard contains the information of total leads, new leads, lead stats graph and etc.

Leads and Junk lead: Leads module contains all the leads details, which is in responsive table. The search option has been provided on the leads module to get search particular lead in very short time. There are two types of searches are present which are Simple Search and Advanced Search.

Customize: The customize module holds all the site labels and lead status. Any customization to the website will be done in this module. Users can customize their website according to their needs.

Report: Reports module maintains the all the reports generated from the Super Admin and his clients. A client can generate a report only once at a time and can send it to their end customers.

Offers: Offers module included the new offers of company. Company can post their discount or any other offers on the website for its customers. Only 3 offers can be posted at a time.

Account: Account section holds the settings of the company profile. Company can change or update their details.
New requests: New requests are generated from the SST License website. If the new user wants to get SST license then he should request it from the our main website. Then the super Admin will activate the new requests and send login credentials.

Company details: Company Details module comes under Super Admin. This module holds all the company details which are activated or in progress.

Ends User: End-user the customers who need to install solar panels on their house roof. Ends users directly interact with the SST website and feed their details. These details taken and provide services to those users.

\section{RESULTS}

\section{Detailed Layout}

Quick and detailed layout of array for size and shading. Users can generate their solar installation report in a simple and effective format.

\section{Price Quote}

User can achieve the perfect quotation for the solar panel installation on their roof area. By using this quotation installers will get the rough idea of price, how much amount will be required to install the solar panel?

\section{Analysis}

The application will provide the rough design of solar panel installation. Depending on the environmental effects it will be designed and installed on the building roof area.

\section{Application Layout}

Companies who will buy this application can design their own website using some of the built-in tools provided by our super admin team. Companies can make changes according to their needs and post it on website.

\section{Template Design}

Users can make their own offers template design for its end users. New offers can be added by the company admin as and when needed.

\section{Graph Paper}

Company admins can generate the graphical representation of the sales and installed solar panel in graph manner. 


\section{Follow up}

Using present leads companies can follow up the customers depending on lead data.

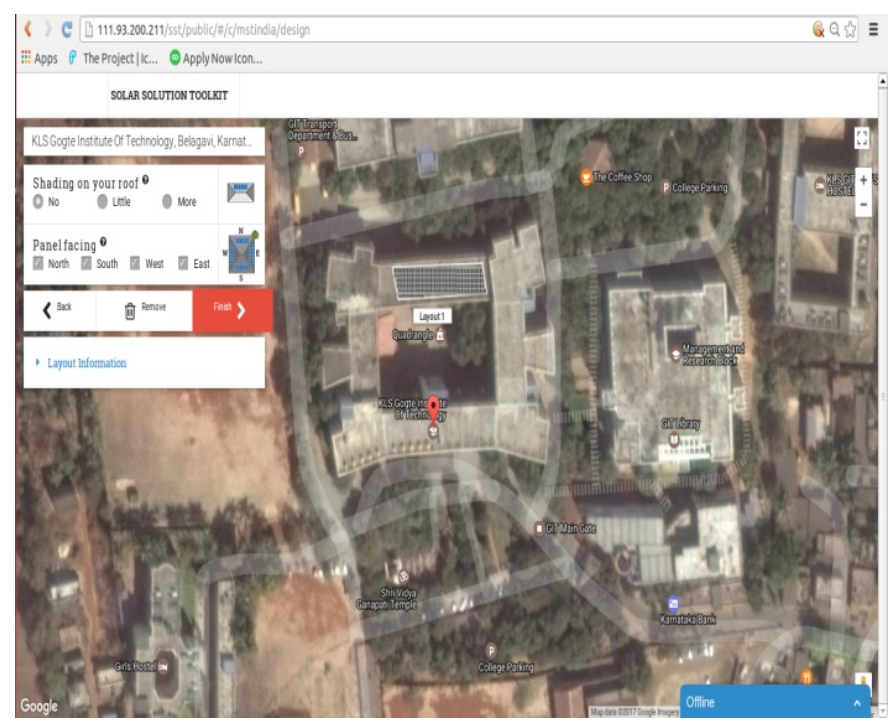

Figure 1. Solar panel Drawn

Here user can draw and place the panel facing according to their environmental status. Panels can be placed on particular directions such as East, West, South and North.

\section{CONCLUSION}

This report describe all about SST License that is "Solar Solution Toolkit License". We tried to fulfill all user requirements with $100 \%$ accuracy. Application is user friendly and responsive, user can use in mobile or tablet or in desktop.

Here Super Admin able to activate new user those you have requested for SST License using New Request module. And also he can view all details from company details module. A company, which use this application can handle all data according to his needs like changing site labels and assumption and can customize whole site according to his needs and can add interesting offers.

\section{REFERENCES}

[1] Jason Gerner, Jeremy Stolz, and Michael K. Glass, "Beginning PHP5, Apache, and MySQL Web Development," Wiley Publishers - January 2004

[2] Thomas Powell, "AJAX: The Complete Reference,"

Tata McGraw-Hill Edition - 2008

[3] Ken Williamson, "Learning AngularJS," O’Reilly - 2015

[4] https://ellislab.com/codeigniter/user-guide

[5] https://developers.google.com/apis-explorer/

[6] https://developers.google.com/apis-explorer/ 